\title{
On the Assessment of non-metallic inclusions by part 13 of API 579 -1/ASME FFS-1 2016
}

\author{
Jorge Luis González-Velázquez, Ehsan Entezari \\ Department of Metallurgy and Materials, Escuela Superior de Ingeniería Quimica e Industrias Extractivas, Instituto Politécnico \\ Nacional, Mexico \\ jlgonalezv@ipn.mx, bttps://orcid.org/0000-0001-6914-4449 \\ ehsan.entezari2014@gmail.com, bttps://orcid.org/0000-0003-3379-1761
}

Jerzy A. Szpunar

Department of Mechanical Engineering, University of Saskatchewan, Canada jersy.szpunar@usask.ca, bttps:/ /orcid.org/0000-0002-1291-8375

ABSTRACT. Improvement of non-destructive inspection techniques has allowed more frequent detection of closely spaced zones of non-metallic inclusions in pressure vessels made of low carbon steel. In the present study, closely spaced inclusions in an in-service cylindrical horizontal pressure vessel were detected by Scan-C ultrasonic inspection and considered as laminations to be assessed by Part 13 of the API 579-1/ASME FFS-1 2016 standard. The outcoming results were considered as a rejection for Level 1 assessment, and a repair or replacement of the component was required, even though it retained a significant remaining strength. Thus, an alternative procedure to assess the mechanical integrity of pressure vessels containing zones of nonmetallic inclusions is proposed by adopting some criteria of the API 5791/ASME FFS-1 Part 13 standard procedure and taking into consideration the dimensions and grouping characteristics of the inclusion zones.

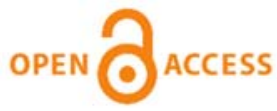

Citation: González-Velázquez, J.L., Entezari, E., Szpunar, J.A., Assessment of non-metallic inclusions by part 13 of API 579 -1/ASME FFS-1 2016, Frattura ed Integrità Strutturale, 59 (2022) 105-114

Received: 28.08.2021

Accepted: 15.10.2021

Published: 01.01.2022

Copyright: (C) 2022 This is an open access article under the terms of the CC-BY 4.0, which permits unrestricted use, distribution, and reproduction in any medium, provided the original author and source are credited.

KEYWORDS. Structural integrity assessment; Non-metallic inclusions Ultrasonic inspection; Pressure vessel.

\section{INTRODUCTION}

7 he presence of non-metallic inclusions (NMIs) in the shell and heads of pressure vessels made of low carbon steel exposed to sour environments in the oil and gas industries is one of the main factors to increase the susceptibility of hydrogen-induced cracking (HIC). According to Gonzalez-Velazquez [1], the interface between the NMIs and the steel matrix is the preferred site for hydrogen trapping and nucleate HIC. Accordingly, the hydrogen originated from hydrogen sulfide $\left(\mathrm{H}_{2} \mathrm{~S}\right)$ and atmospheric moisture traps at the interface between steel matrix and NMIs, increasing molecular hydrogen pressure [2-4]. High molecular hydrogen pressure separates the metallic matrix and inclusions, causing propagation 
of HIC parallel to the pipe wall [5]. Liu et al. [6] and Dong et al. [7] showed that the HIC is commonly associated with clusters of $\mathrm{Si}, \mathrm{Al}, \mathrm{Mn}$, and Ca-based NMIs in steel plates, where the shape, size, and distance between inclusions affect the HIC. Most researchers showed that large inclusions are prone to trap more hydrogen, increasing HIC susceptibility, and concluded that the shape, size, and separation between NMIs are critical factors for HIC propagation [8,9,10]. The connection between HIC and NMIs has been of great concern for pressure vessel users in the oil and gas industry, leading to the need to assess the impact of NMIs on the Fitness-For-Service (FFS) of pressure vessels. However, because of the absence of a specific assessment procedure, NMIs are usually evaluated as laminations.

Laminations are made by the plane with weaker texture parallel to the rolling plane and have a higher risk of cracking at high hydrogen pressure [11]. Molecular hydrogen pressure in lamination zones is higher than in other areas, leading to the stress fields at plastic zones of crack tips which trigger the HIC propagation [12]. Moussa et al. [13] reported that high hydrogen pressure between 2 laminations increased the stress intensity factor for HIC, causing crack growth at the critical pressure.

The detection of zones of closely spaced NMIs in pressure vessels is typically done by conventional straight beam ultrasonic inspection in Scan-C mode. It is a common practice by the inspectors to report them as laminations. Gomera et al. [14] observed that signs of continuous laminations are associated with the accumulation of NMIs in hot rolled carbon steel plates. González et al. [15] analyzed the mechanical behavior of non-coplanar pressurized laminations in carbon steel pipes. They observed that the laminations might be interconnected by plastic deformation and then create a larger damaged area. The FFS assessment of pressure vessels containing laminations is done by Part 13 of standard API 579 -1/ASME FFS-12016 [16]. This standard illustrates 3 assessment Levels. Level 1 assessment is the most conservative method, evaluating lamination zones from the perspective of metal loss with a minimum amount of inspection. Level 1 assessment commonly proposes a reduction of internal pressure of pressure vessels for maintaining safety. [17,18]. In the Level 2 assessment, lamination zones are considered as local thinner areas or a crack-like flaw and evaluated by criteria such as remaining strength factor (RSF) and failure assessment diagram (FAD) [19]. The Level 3 assessment also is done using the Finite Element Method (FEM) for explicit modeling and the most accurate stress analysis of lamination zones, considering defects geometry and loading conditions $[17,20]$.

The equipment's Owners/Users often question the assessment criteria of API 579 and request FFS engineers to provide technical advice for modifying the system due to the high financial cost. Thus, the FFS assessment of zones containing groups of NMIs can be done by methods similar to those used for laminations but with less strict assessment criteria.

The present research aims to adapt the FFS assessment procedure and criteria presented in Part 13 of the API 579-1/ASME FFS-1 standard to assess zones of non-metallic inclusions in pressure vessel shells made of low carbon steel.

\section{THEORETICAL OVERVIEW: SCOPE AND ASSESSMENT CRITERIA OF NON-METALLIC INCLUSIONS BY PART 13 OF API 579-1/ASME FFS-1 STANDARD}

\section{Definition and applicability criteria of non-metallic inclusion rone}

7 he NMIs are not considered as defects by any code, standard, or technical specification of mechanical integrity or FFS. Nonetheless, as NMIs are parallel to the shell wall in non-destructive inspections, they are considered as laminations for assessment purposes by structural integrity engineers. The dimensioning of zones of NMIs is based on the guidelines of API 579, as indicated in Fig. 1. The non-destructive inspection of zones of NMIs is typically done by industrial ultrasonic testing, using a straight beam or phased array [16].

\section{Definition and applicability criteria of laminations}

Paragraph 13.1.2 of the API 579 standard defines laminations as non-fusion planes inside a steel plate produced in the fabrication process, and they may exist in one or more planes in the plate. Laminations are planar defects, so they do not produce bulging on the metal surface, have no cracking in the direction of the thickness, and are not interconnected [16]. According to paragraph 13.4.2.1 of API 579 Part 13, the Level 1 assessment procedure of laminations in a Type A component, a component with a specific design code, subjected to internal pressure is the following [16]:

STEP 1. Obtain the significant dimensions of the lamination (see Fig. 1).

STEP 2. Determine $t_{c}=t_{r d}-F C A$

STEP 3. If there are two or more laminations in the same plane and it is met that $L_{s}<2 t_{c}$, they must be combined as a single lamination with longitudinal $(s)$ and circumferential $(c)$ dimensions adjusted to the total size of the zone containing the laminations.

STEP 4. Verify if the edge of the lamination closest to a major structural discontinuity is at a distance 
$L_{m s d} \geq 1.8 \sqrt{D t_{c}}$.

STEP 5. Verify if the vertical separation between the edge of multiple laminations weld meets $L_{b} \leq 0.09 \max [s, c]$, and $L_{b} \leq \min \left[t_{c} / 3,0.5 \mathrm{in}\right]$.

STEP 6. Verify that there is no cracking through the thickness and the lamination is not surface breaking, according to $t_{m m} \geq 0.01 t_{c}$.

STEP 7. Verify if the distance between the edge of the lamination and the nearest weld satisfies $L_{W} \geq \max \left[2 t_{c}, 25 \mathrm{~mm}(0.1 \mathrm{in})\right]$.

STEP 8. If the lamination is in a hydrogen charging environment, the lamination dimensions must satisfy $s, c \leqslant 0.6 \sqrt{D t_{c}}$.

STEP 9. If the conditionals of steps 4 to 8 are met, the lamination is acceptable by the Level 1 assessment, and consequently, no corrective action is required. Otherwise, the component is rejected, a Level 2 assessment is recommended.

STEP 10. Determine the $M A W P_{r}$ using $t_{c}$ from STEP 2 (equations are provided in Annex 2C of API 579 standard).

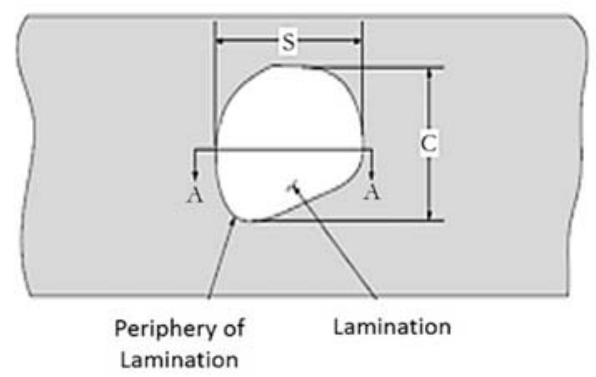

Lamination Plan View

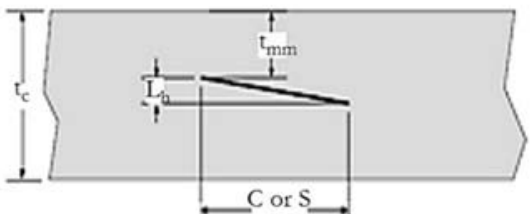

Section A-A

Cross Section of Lamination

Figure 13.2- Typical Lamination

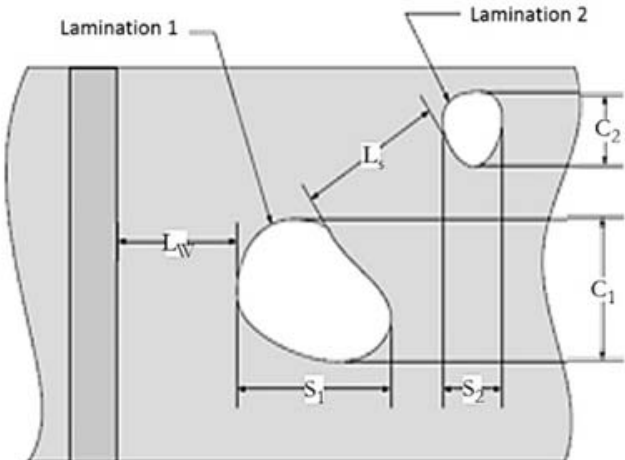

a) Planar View of Lamination Plan View Close to A Weld Seam And to Other Laminations

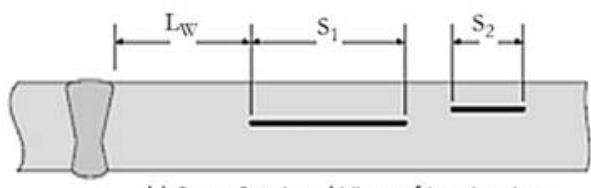

b) Cross Sectional View of Laminations Close to A Weld Seam And to Other Laminations

Figure 13.3-Weld Joint Spacing and Multiples Laminations

Figure 1: Significant dimensions for assessing laminations as established in Figs 13.2 and 13.3 of API 579-1/ASME FFS-1 2016.

The Level 2 assessment procedure considers the lamination as a local thin area with a remaining thickness equal to the maximum value of $\left[t_{c}-L_{h}-t_{m m}\right]$, or $t_{m m}$. In this case, the zones containing laminations are evaluated by Part 5 of the API 579. However, if the $L_{b}$ criterion of STEP 5 above is not satisfied, the lamination is evaluated as a crack-like flaw using Level 2 methodology of Part 9 of API 579, where the crack depth $2 a=L_{b}$. Obviously, the above criteria lead to overconservative assessments, and even innocuous zones of NMIs (regarded as laminations) with a few inches in length are rejected.

\section{FFS ASSESSMENT OF ZONES OF NON-METALLIC INCLUSIONS}

$\mathrm{I}$

n order to analyze the FFS assessment procedure of a pressure vessel with zones of NMIs, a real-life case was used. Fig. 2 shows a photograph of the pressure vessel containing zones of NMIs, as installed and operated in an oil 
production offshore facility. This case was of critical importance to the owner due to the high costs of repair and the extreme consequences of failure.

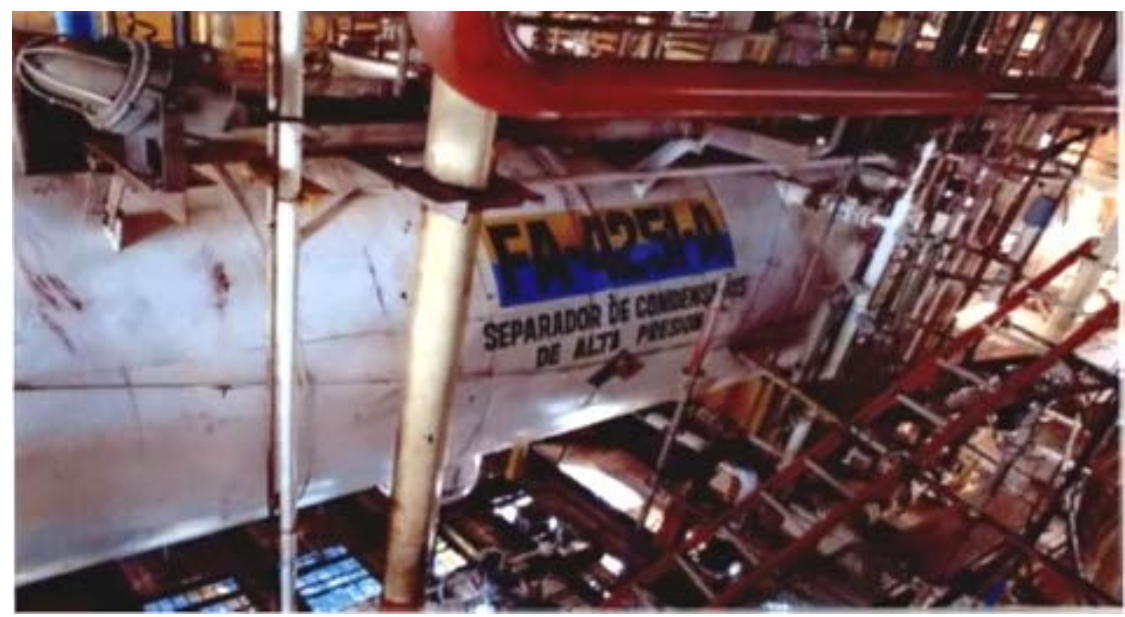

Figure 2: Photograph of the assessed pressure vessel installed and operated in an oil production offshore facility.

\begin{tabular}{ll}
\hline Type of component & Cylindrical horizontal, torispherical heads, welded \\
Service & Sour gas/condensate separator \\
Design code & ASME Sec. VIII, Div. 1 \\
Material specification & SA 516 Gr. 70 \\
Operating pressure & $14.2 \mathrm{psi}$ \\
Maximum Allowable Working Pressure (MAWP) & $42.6 \mathrm{psi}$ \\
Service temperature & $95^{\circ} \mathrm{F}$ \\
External diameter (D) & $122 \mathrm{in}$ \\
Nominal thickness ( $\left.\mathrm{t}_{\text {nom }}\right)$ & 1 in \\
Minimum required wall thickness ( $\left.\mathrm{t}_{\text {min }}\right)$ & 0.130 in \\
Future Corrosion Allowance $(\mathrm{FCA})$ & 0.125 in \\
\hline
\end{tabular}

Table 1: Technical data of the pressure vessel.

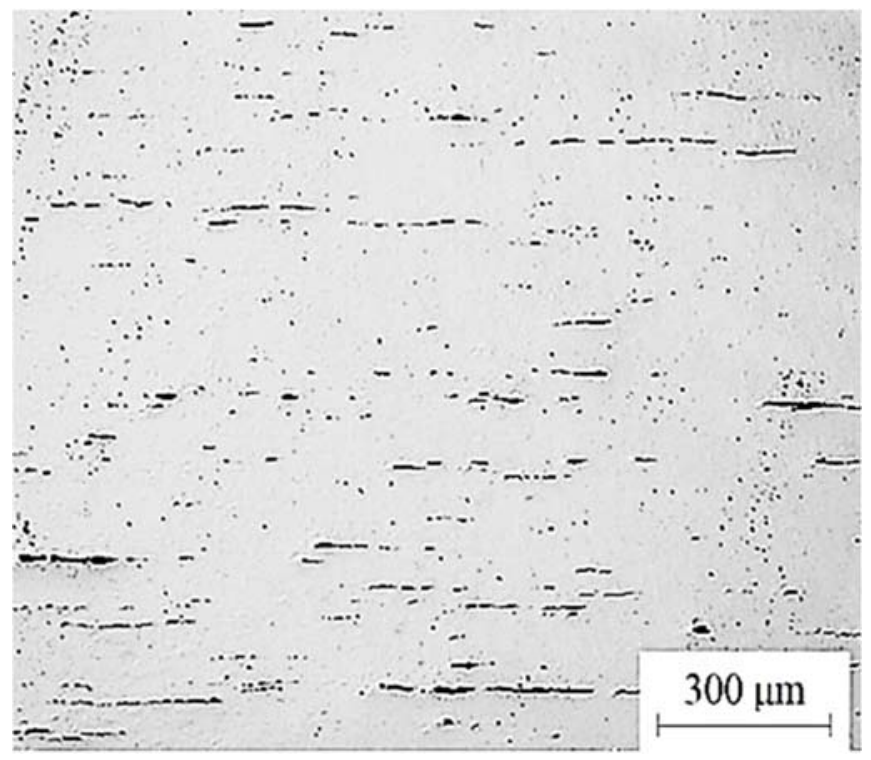

Figure 3: The typical distribution of non-metallic inclusions in the vessel shell. As-polished sample and bright-field metallographic microscope. 
Tab. 1 summarizes the main technical data of the assessed pressure vessel. The appearance of the NMIs was determined by the metallography of a coupon extracted from a previous repair and is shown in Fig. 3. The inclusions were identified as Type A, thick series, according to the ASTM E45 standard [21]. Fig. 4 shows a drawing of the pressure vessel. The inclusion zones were detected in the shell plates ENV-2 and ENV-3 and the heads TP-1 and TP-2.

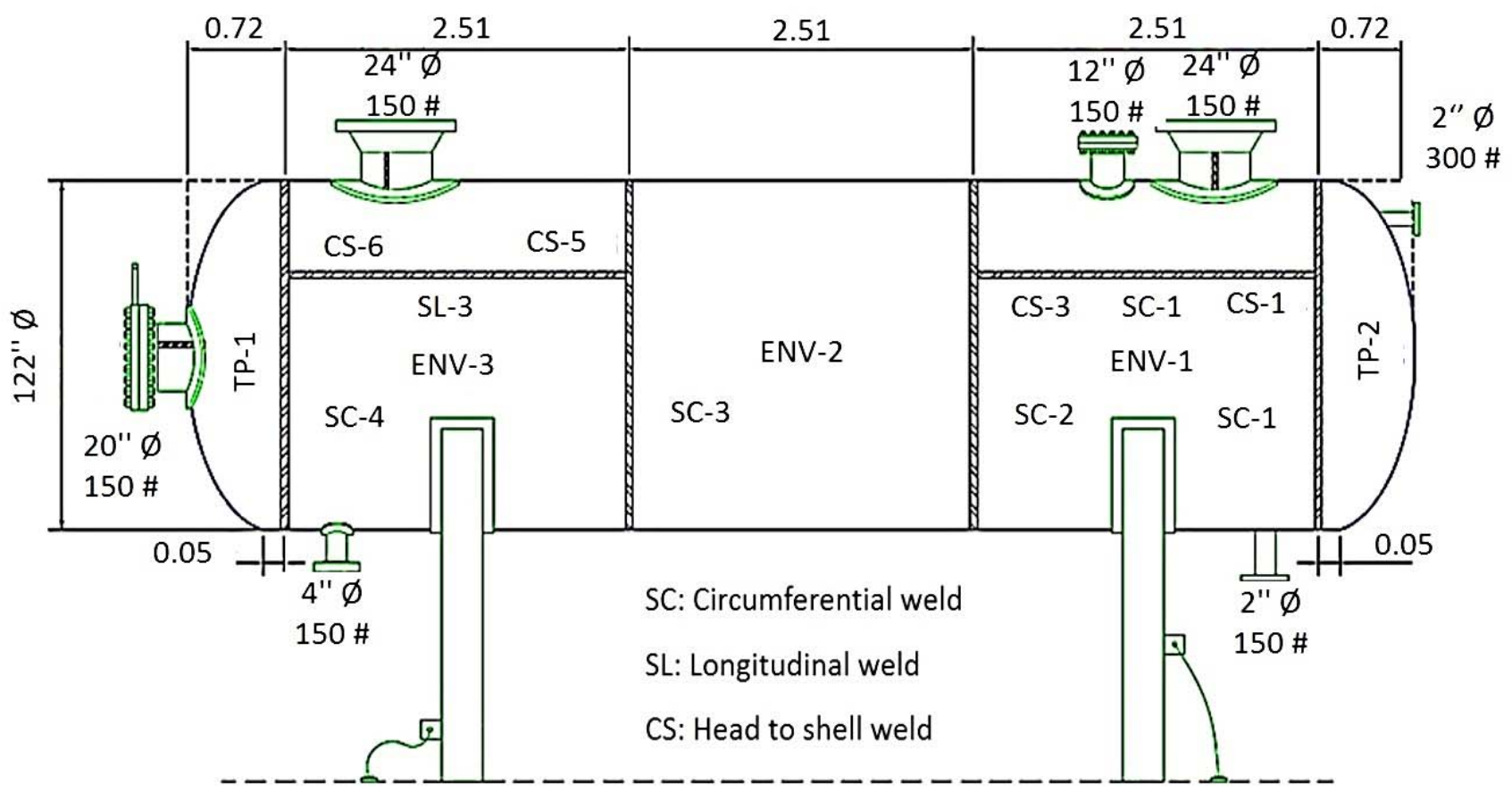

Figure 4: Pressure vessel design drawing, indicating the identification tags of the shell plates.

The zones of NMIs were detected by phased array ultrasonic testing (PAUT) in Scan-C mode. Fig. 5 shows detected zones of NMIs, along with the corresponding PAUT screen record. Of the 5 zones of NMIs detected, one is close to a weld joint (ENV-3.2), and the other is isolated (TP-1.6). It is noted that the zones are planar and not interconnected and also spread across a significant portion of the thickness.
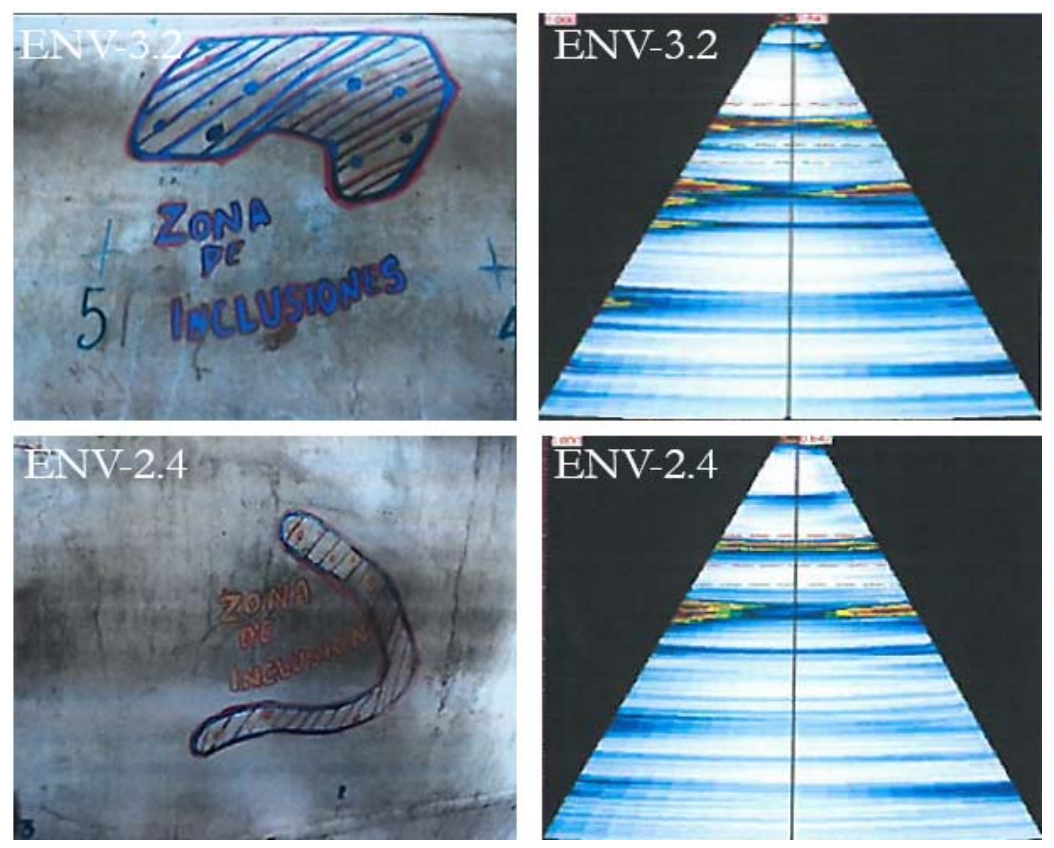

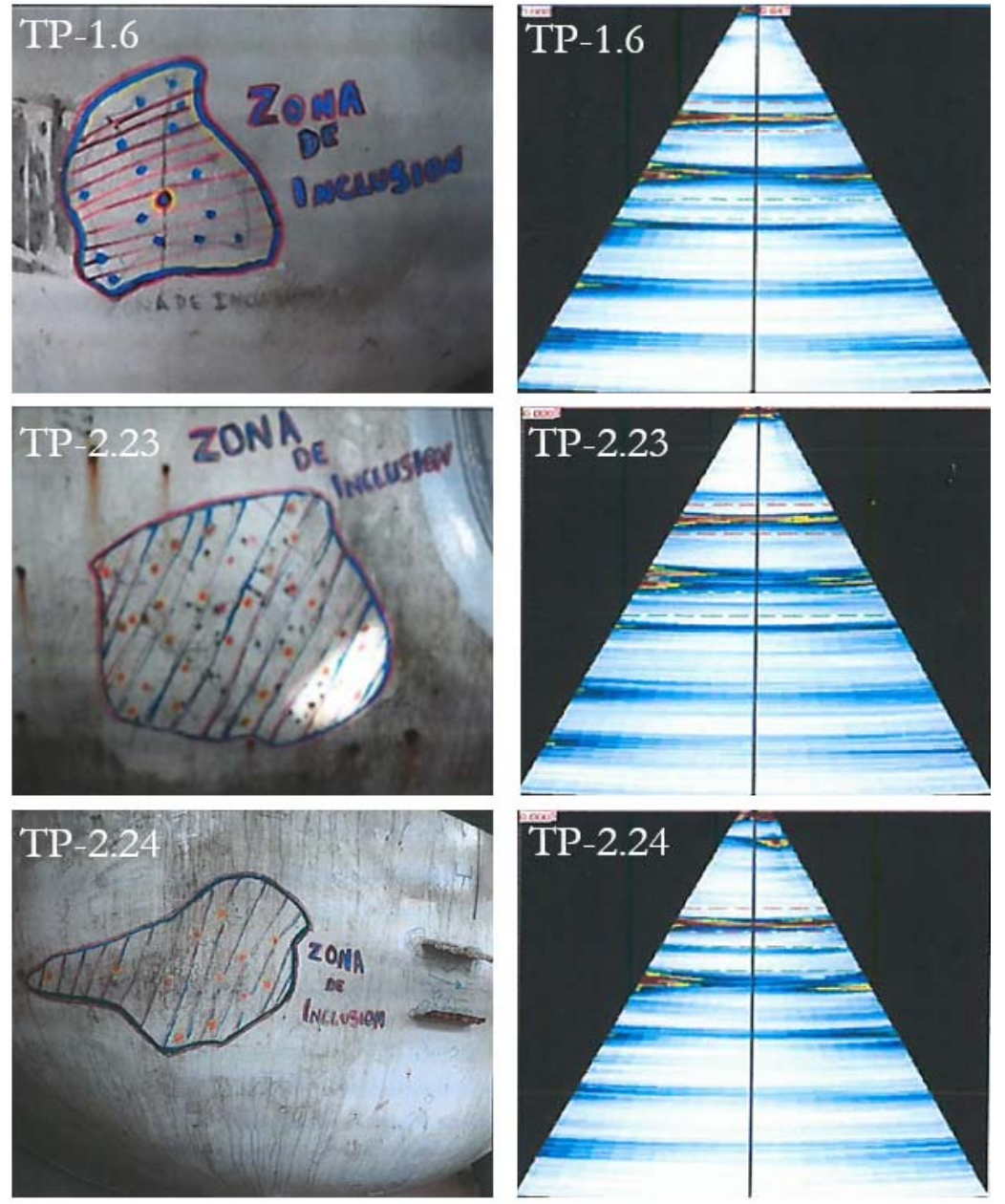

Figure 5: Photographic records of zones of non-metallic inclusions detected by PAUT in the pressure vessel.

Tab. 2 shows the dimensions of the zones of NMIs detected by the non-destructive inspection in the pressure vessel.

\begin{tabular}{ccccccccc}
\hline $\begin{array}{c}\text { Defect } \\
\text { ID }\end{array}$ & $\begin{array}{c}\text { Wall } \\
\text { thickness } \\
\text { away of } \\
\text { lamination } \\
\left(t_{r d}\right)\end{array}$ & $\begin{array}{c}\text { Long. } \\
\text { dimension }(s)\end{array}$ & $\begin{array}{c}\text { Circ. } \\
\text { dimension }(c)\end{array}$ & $\begin{array}{c}\text { Minimum } \\
\text { measured } \\
\text { thickness } \\
\left(t_{m m}\right)\end{array}$ & $\begin{array}{c}\text { Lamination } \\
\text { height } \\
\left(L_{b}\right)\end{array}$ & $\begin{array}{c}\text { Lamination } \\
\text { to } \\
\text { lamination } \\
\text { spacing } \\
\left(L_{s}\right)\end{array}$ & $\begin{array}{c}\text { Spacing to a } \\
\text { nearest major } \\
\text { discontinuity } \\
\left(L_{m s}\right)\end{array}$ & $\begin{array}{c}\text { Spacing } \\
\text { to nearest } \\
\text { weld joint } \\
\left(L_{m}\right)\end{array}$ \\
ENV-3.2 & 1.046 & 16.00 & 14.00 & 0.296 & 0.630 & 40 & 35.83 & 0.5 \\
ENV-2.4 & 1.014 & 13.00 & 10.00 & 0.582 & 0.242 & 40 & 13.78 & 14.0 \\
TP-1.6 & 1.098 & 7.50 & 6.50 & 0.296 & 0.720 & 22.5 & 16.50 & 30.0 \\
TP-2.23 & 1.112 & 14.00 & 16.50 & 0.287 & 0.552 & 16.5 & 3.00 & 34.0 \\
TP-2.24 & 1.112 & 12.50 & 22.00 & 0.278 & 0.616 & 16.5 & 6.00 & 17.5 \\
\hline
\end{tabular}

Table 2: Dimensions of the zones of non-metallic inclusions detected in the pressure vessel (All dimensions in inches).

\section{FFS ASSESSMENT OF INCLUSION ZONES BY PART 13 OF API 579}

$\mathrm{T}$

ab. 3 presents the results of Part 13 of API 579 Level 1 assessment of the zones of non-metallic inclusions listed in Tab. 2, regarding them as laminations, and evaluated according to the procedure described in section 2.2 of this paper. The sequence of steps was modified to display the calculations in a rational order. 
J.L. González.-Velázquez et alii, Frattura ed Integrità Strutturale, 59 (2022) 105-114; DOI: 10.3221/IGF-ESIS.59.08

\begin{tabular}{|c|c|c|c|c|c|}
\hline Step/criterion & ENV-3.2 & ENV-2.4 & TP-1.6 & TP-2.23 & TP-2.24 \\
\hline$t_{c}=t_{r d}-F C A$ & 0.921 & 0.899 & 0.973 & 0.987 & 0.987 \\
\hline $1.8 \sqrt{D t_{c}}$ & 19.080 & 18.850 & 19.611 & 19.752 & 19.752 \\
\hline $0.01 t_{c}$ & 0.009 & 0.009 & 0.010 & 0.010 & 0.010 \\
\hline $2 t_{c}$ & 1.842 & 1.798 & 1.946 & 1.974 & 1.974 \\
\hline$L_{s}<2 t_{c}$ & Yes & Yes & Yes & Yes & Yes \\
\hline$L_{m s d} \geq 1.8 \sqrt{D t_{c}}$ & Yes & No & No & No & No \\
\hline$t_{m m} \geq 0.01 t_{c}$ & Yes & Yes & Yes & Yes & Yes \\
\hline$L_{W} \geq \max \left[2 t_{c}, 0.1 \mathrm{in}\right]$ & No & Yes & Yes & Yes & Yes \\
\hline $0.09 \max [s, c]$ & 1.440 & 1.170 & 0.675 & 1.485 & 1.98 \\
\hline$L_{h} \leq 0.09 \max [s, c]$ & Yes & Yes & No & Yes & Yes \\
\hline$t_{c} / 3$ & 0.307 & 0.210 & 0.324 & 0.239 & 0.239 \\
\hline$L_{b} \leq \min \left[t_{c} / 3,0.5 \mathrm{in}\right]$ & No & No & No & No & No \\
\hline $0.6 \sqrt{D t_{c}}$ & 4.497 & 4.443 & 4.623 & 4.656 & 4.656 \\
\hline$s, c \leq 0.6 \sqrt{D t_{c}}$ & No & No & No & No & No \\
\hline$M A W P r$ & 299 psi & $292 \mathrm{psi}$ & 207 psi & 206 & 206 \\
\hline Result & Rejected & Rejected & Rejected & Rejected & Rejected \\
\hline
\end{tabular}

Table 3: Level 1 assessment of the zones of non-metallic inclusions by Part 13 of API 579 in the pressure vessel. (All dimensions in inches).

Tab. 4 shows the results of the Level 2 assessment. Since the $L_{b} \leq \min \left[t_{c} / 3,0.5 \mathrm{in}\right]$ criterion was not satisfied, zones of NMIs were assessed as a crack-like flaw using Level 2 methodology of Part 9 of API 579. For this aim, $2 a=L_{b}$ and $2 c=\max [s, c]$, the ligament length $d=t_{m m}$, and the thickness was $t_{r d}$, as listed in Tab. 2. The Level 2 assessment also was done by a commercial fracture mechanics application software. Further, the mechanical properties of the SA $516 \mathrm{Gr} .70$ steel were taken at the nominal values YS $=38 \mathrm{ksi}$ and UTS $=70 \mathrm{ksi}$ and assuming a $\mathrm{K}_{\mathrm{IC}}=100 \mathrm{ksi} \sqrt{\mathrm{in}}$. The reference stresses were inferred from the internal pressure.

\begin{tabular}{cccccc}
\hline Step/criterion & ENV-3.2 & ENV-2.4 & TP-1.6 & TP-2.23 & TP-2.24 \\
Kr & 0.621 & 0.063 & 0.015 & 0.012 & 0.014 \\
Lr & 0.126 & 0.078 & 0.061 & 0.057 & 0.278 \\
Location of assessment point in the & Inside & Inside & Inside & Inside & Inside \\
FAD envelope & & & & & \\
RSF & 1.57 & 15.7 & 19.1 & 22.7 & 20 \\
Result & Accepted & Accepted & Accepted & Accepted & Accepted \\
\hline
\end{tabular}

Table 4: Level 2 assessment of the zones of non-metallic inclusions by Part 9 of API 579 in the pressure vessel.

\section{RESULTS AND DISCUSSION}

A s expected, the Level 1 assessment by Part 13 of API 579 rejected all five defects, failing three out of seven criteria. Nonetheless, the $M A W P_{r}$ calculated with the reduced thickness was much higher than the $M A W P$. The criteria that caused rejection in all cases were the lamination height $\left(L_{b}\right)$ which ratio $L_{b} / t_{r d}$ variated from 0.6 to 0.5 , and the lamination size $(s, c)$, where the allowable size ranged from 4.443 to 4.656 in, while the maximum length of the zones of NMIs was from 22 in to 7.5 in. The next most important factors were the spacing to a major structural discontinuity $\left(L_{m s d}\right)$ and the distance to the nearest weld joint $\left(L_{m}\right)$; a combination of these two factors was a cause of rejection. 
In the Level 2 assessment, however, all five defects were acceptable and more important; the assessment points were in the lower right corner of the $F A D$, indicating that the severity of the defects is quite low, even though they were assessed as crack-like defects. The only defect that was more far away from the origin of the $F A D$ was ENV-3.2, a defect zone in the vicinity of weld metal with $R S F$ of 1.57 . Although the defect ENV-3.2 has similar dimensions and a similar $\mathrm{L}_{\mathrm{h}} / \mathrm{t}_{\mathrm{rd}}$ ratio with the defect TP-2.23, the RSF of defect ENV-3.2 is much lower than that of defect TP-2.23, as shown in Fig. 6. Thus, the proximity of the defect ENV-3.2 to a weld metal is the main factor that decreased the RSF. Further, the rest of the defects have RSF greater than 15, which indicates that the pressure vessel containing laminations as large as 16 in long and occupying as much as $60 \%$ of the thickness still retain sufficient strength to remain in service.

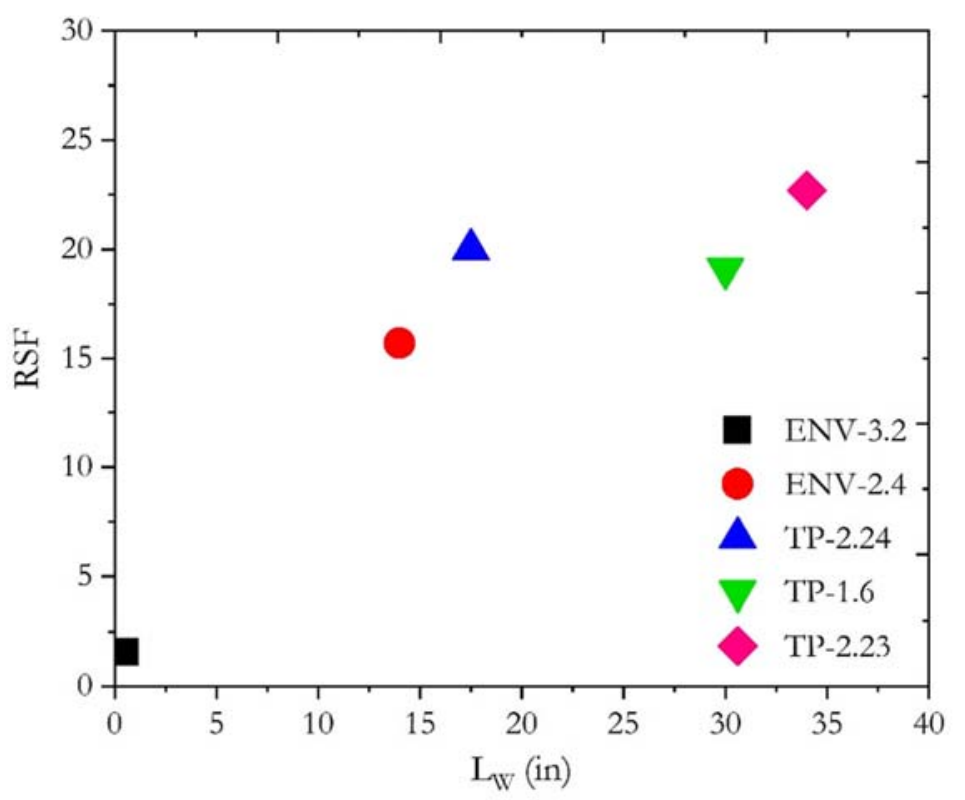

Figure 6: Variation of remaining strength factor with spacing to the nearest weld joint.

Based on the above observations, the following rules can be adopted to perform FFS assessments of zones of NMIs inclusions in pressure vessels made of low carbon steel, based on the procedure of Part 13 of API 579:

1. The most important dimensions for the assessment are the lamination size $(s, c)$, and the spacing to the nearest weld joint $\left(L_{m}\right)$.

2. The lamination height $\left(L_{b}\right)$ can be disregarded since it may cause unnecessary rejections and additionally has a minor effect on the RSF when the NMIs zone is evaluated as a crack-like defect. This is due to the fact that NMIs are discontinuous and disperse across the thickness, so they do not introduce a significant reduction of the effective cross-section area, nor are significant stress concentrators.

3. The criterion $s, c \leq 0.6 \sqrt{D t_{c}}$ can be disregarded because of the discontinuous and disperse nature of the NMIs. Therefore, longitudinal and circumferential dimensions of NMIs do not affect the remaining strength.

4. If possible, it is advisable to leave out the Level 1 assessment and directly perform the Level 2 assessment since it provides a less conservative assessment when the NMIs zone is evaluated as a crack-like defect.

\section{CONCLUSION}

he Fitness-For-Service assessment of pressure vessels containing zones of closely spaced non-metallic inclusions can be effectively performed, assuming that the defect is considered as lamination and evaluated by Part 13 of the API 579 standard. For Level 1 assessments, the most important dimensions are the lamination size $(s, c)$, and the spacing to the nearest weld joint $\left(L_{m}\right)$, while the lamination height $\left(L_{b}\right)$ and the $s, c<0.6 \sqrt{ }\left(D t_{c}\right)$ criteria can be disregarded since it is very likely that the defect will be rejected because of these, and the discontinuity and dispersion of non-metallic inclusions across the thickness do not introduce significant reduction of the effective cross-section area, nor are relevant stress concentrators. Finally, if possible, it is advisable to skip the Level 1 assessment and directly perform the Level 2 
assessment considering the non-metallic inclusion as a buried crack-like defect since it provides less conservative assessments.

\section{ACKNOWLEDGMENTS}

he authors would like to acknowledge the National Polytechnic Institute (IPN), the National Council of Science and Technology (CONACYT), and the Grupo de Análisis de Integridad de Ductos (Group of Pipeline Integrity Analysis) of the Instituto Politécnico Nacional (IPN) for the support to carry out this research.

\section{REFERENCES}

[1] González-Velázquez, J.L. (2021). Fatigue and environmentally assisted crack propagation. A Practical Approach to Fracture Mechanics. DOI: 10.1016/B978-0-12-823020-6.00006-2.

[2] Mohtadi-Bonab, M.A., Eskandari, M., Karimdadashi, R., Szpunar, J.A. (2017). Effect of different microstructural parameters on hydrogen-induced cracking in an API X70 pipeline steel, Met. Mater. Int., 23(4), DOI: 10.1007/s12540-017-6691-z.

[3] Mohtadi-Bonab, M.A., Eskandari, M. (2017). A focus on different factors affecting hydrogen-induced cracking in oil and natural gas pipeline steel, Eng. Fail. Anal., 79, DOI: 10.1016/j.engfailanal.2017.05.022.

[4] Pedeferri, P. (2018). Hydrogen-Induced Damage. Corrosion Science and Engineering, Springer, pp. 275-295. DOI: 10.1007/978-3-319-97625-9.

[5] Wasim, M., Djukic, M.B. (2020). Hydrogen embrittlement of low carbon structural steel at macro-, micro-and nanolevels, Int. J. Hydrogen Energy, 45(3), pp. 2145-2156. DOI: 10.1016/j.ijhydene.2019.11.070.

[6] Liu, Z.Y., Wang, X.Z., Du, C.W., Li, J.K., Li, X.G. (2016). Effect of hydrogen-induced plasticity on the stress corrosion cracking of X70 pipeline steel in simulated soil environments, Mater. Sci. Eng. A, 658,

DOI: 10.1016/j.msea.2016.02.019.

[7] Dong, C.F., Liu, Z.Y., Li, X.G., Cheng, Y.F. (2009). Effects of hydrogen-charging on the susceptibility of X100 pipeline steel to hydrogen-induced cracking, Int. J. Hydrogen Energy, 34(24), DOI: 10.1016/j.ijhydene.2009.09.090

[8] Peng, Z., Liu, J., Huang, F., Hu, Q., Cao, C., Hou, S. (2020). Comparative study of non-metallic inclusions on the critical size for HIC initiation and its influence on hydrogen trapping, Int. J. Hydrogen Energy, 45(22), DOI: 10.1016/j.ijhydene.2020.02.131.

[9] Kim, W.K., Koh, S.U., Yang, B.Y., Kim, K.Y. (2008). Effect of environmental and metallurgical factors on hydrogen-induced cracking of HSLA steels, Corros. Sci., 50(12), pp. 3336-3342.

DOI: $10.1016 /$ j.corsci.2008.09.030.

[10] Rahman, K.M.M., Mohtadi-Bonab, M.A., Ouellet, R., Szpunar, J., Zhu, N. (2019). Effect of electrochemical hydrogen charging on an API X70 pipeline steel with focus on characterization of inclusions, Int. J. Press. Vessel. Pip., 173, pp. 147-155. DOI: 10.1016/j.ijpvp.2019.05.006.

[11] Gonzalez, J.L., Ramirez, R., Hallen, J.M., Guzman, R.A. (1997). Hydrogen-Induced Crack Growth Rate in Steel Plates Exposed to Sour Environments, Corros., 53(12), Doi: 10.5006/1.3290278. DOI: 10.5006/1.3290278.

[12] Servin, A., González, J.L., Morales, A. (2009). Behavior of coplanar and non-coplanar laminations in API5L X52 steel simulated by finite elements, Inf. Tecnológica, pp. 97-106. DOI: 10.1612/inf.tecnol.4113it.08.

[13] Moussa, W.A., Bell, R., Tan, C.L. (1999). The interaction of two parallel semi-elliptical surface cracks under tension and bending, J. Press. Vessel Technol. Trans. ASME, 121(3), DOI: 10.1115/1.2883710.

[14] Gomera, V.P., Sokolov, V., Fedorov, V., Okhotnikov, A.A. and Saykova, M.S. (2010). Use of AE method for detection of steel lamination in the industrial pressure vessel, J. Acoust. Emiss., 28, pp. 234-245.

[15] Gonzalez, J.L., Morales, A. (2006). Analysis of Non-Coplanar the Pressurized Laminations in X52 Steel Pipes by NonLinear by Finite Element. International Pipeline Conference, vol. 42622, pp. 791-8. DOI: 10.1115/IPC2006-10514.

[16] A.P.I. (2016). Fitness-for-service: API 579-1/ASME FFS-1, American Petroleum Institute.

[17] Anderson, T.L., Osage, D.A. (2000). API 579: A comprehensive fitness-for-service guide, Int. J. Press. Vessel. Pip., 77(14-15), DOI: 10.1016/S0308-0161(01)00018-7. 
[18] Purnana, P., Ibrahim, S. (2019). Fitness for service assessment of cross-country oil pipelines based on API 579 (application of API 579 on ASME B 31.4). ASME 2019 India Oil and Gas Pipeline Conference, IOGPC 2019. DOI: $10.1115 /$ IOGPC2019-4555.

[19] Jaske, C.E., Rubal, M.J. (2010). Fitness for Service document comparison: API 579 vs. PDAM. Proceedings of the Biennial International Pipeline Conference, IPC, 1. DOI: 10.1115/IPC2010-31552.

[20] Fernández-Cueto, M.J., Capula-Colindres, S., Angeles-Herrera, D., Velázquez, J.C., Méndez, G.T. (2018). Analysis of 3D planar laminations in a welded section of API 5L X52 applying the finite element method, Soldag. e Insp., 23(1), DOI: 10.1590/0104-9224/SI2301.03.

[21] ASTM. (2018). E 45-18a Standard Test Methods for Determining the Inclusion Content of Steel, ASTM Int. Conshohocken, PA, www.astm.org, (C).

\section{NOMENCLATURE}

c lamination dimension in the circumferential direction

D inside diameter of the component

FCA future corrosion allowance

FAD failure assessment diagram

$\mathrm{L}_{\mathrm{h}} \quad$ depth of the defects to the external surface

$\mathrm{L}_{\mathrm{msd}} \quad$ spacing to the nearest major structural discontinuity

$\mathrm{L}_{\mathrm{s}} \quad$ lamination-to-lamination spacing

$\mathrm{L}_{\mathrm{w}} \quad$ spacing to the nearest weld joint

MAWP maximum allowable working pressure

MAWP reduced maximum allowable working pressure

NMIs non-metallic inclusions

RSF remaining strength factor

$\mathrm{s} \quad$ lamination dimension in the longitudinal direction

$t_{c} \quad$ corroded wall thickness

$\mathrm{t}_{\min } \quad$ thickness required to support the internal pressure in the pressure vessel

$t_{\mathrm{mm}} \quad$ minimum measured thickness

$t_{\text {nom }} \quad$ nominal thickness of the component

$t_{\mathrm{rd}} \quad$ wall thickness away of lamination 